\title{
Pengaruh Bagian Setek dan Lama Perendaman Ekstrak Daun Kelor terhadap Pertumbuhan Bibit Sirih Daun (Piper betle, L.)
}

Maria Imelda Humoen ${ }^{\text {a }}$

${ }^{a}$ Fakultas Pertanian, Universitas Timor, Kefamenanu, TTU - NTT, Indonesia.

\section{Article Info}

\section{Article history:}

Received 29 Mei 2017

Received in revised form 22 Juni 2017

Accepted 9 Agustus 2017

Keywords:

Sirih Daun

Bagian Setek

Ekstrak Kelor

\section{Abstrak}

Penelitian ini bertujuan untuk mengetahui pengaruh bagian setek dan lama perendaman dalam ekstrak daun kelor terhadap pertumbuhan bibit sirih daun serta memperoleh bagian setek dan lama perendaman dalam ekstrak daun kelor yang memberikan pertumbuhan bibit sirih daun yang terbaik. Dua bagian setek, pucuk dan tengah direndam dalam ekstrak kelor selama 1, 3 dan 5 jam dan dilakukan dalam sebuah percobaan pot yang disusun menurut rancangan acak kelompok faktorial dengan tujuh ulangan. Penelitian ini dilaksanakan pada JanuariApril 2016 di Kebun Percobaan Fakultas Pertanian Universitas Timor, Kefamenanu, TTU, NTT, Indonesia. Hasil penelitian menunjukkan setek yang berasal dari bagian tengah dengan lama perendaman 3 jam menghasilkan pertumbuhan bibit sirih yang paling baik, laju pertumbuhan tunas $(0,24 \mathrm{~g} / \mathrm{minggu})$, laju asimilasi bersih $\left(0,0044 \mathrm{~g} / \mathrm{cm}^{2} / \mathrm{minggu}\right)$, Rasio tajuk akar $(5,01 \mathrm{~g})$ bobot kering tunas $(1,76 \mathrm{~g})$. (C2017 dipublikasikan oleh Savana Cendana.

\section{Pendahuluan}

Sirih daun (Piper betle, L.) dapat diperbanyak secara vegetatif melalui setek batang dan pencangkokan (Lusiana et al., 2013). Penyetekan pada tanaman sirih daun yang digunakan berasal dari potongan batang bertujuan agar bagian tersebut membentuk akar dan tunas. Danu dan Nurhasybi (2003) menambahkan bahwa, sumber bahan setek yang berasal dari bagian batang yang berbeda memiliki kualitas yang berbeda karena mengalami masa perkembangan yang berbeda Bahan setek yang diambil dari bagian tanaman yang lebih tua tingka keberhasilan setek sirih daun lebih tinggi (Prastowo et al, 2006) mencapai 40-70 $\%$ (Sudewo, 2010), hal ini dikarenakan kandungan karbohidrat dan auksin (hormon) cukup memadai untuk menunjang terjadinya perakaran setek. Pada batang yang masih muda kandungan karbohidratnya rendah tetapi hormonnya cukup tinggi, maka hasil setekkan akan tumbuh tunas terlebih dahulu (Prastowo et al., 2006) dan tingkat keberhasilannya lebih rendah yaitu 30\% (Sudewo, 2010), akan tetapi setek yang baik harus tumbuh akar dulu (Prastowo et al, 2006), dan memiliki keseimbangan pertumbuhan antara akar dan tunas (Suwandiyati, 2009).

Bagian sulur yang digunakan adalah sulur panjat yang pada buku-bukunya memiliki akar lekat yang berfungsi untuk menempel di batang pohon. Bagian dari sulur panjat yang digunakan sebagai bahan setek yaitu bagian tengah dan bagian pucuk sulur yang masing-masing memiliki 4 buku, yang panjangnya 25 $\mathrm{cm}$.

Beberapa petani yang menggunakan ZPT lebih memilih ZPT yang sudah beredar di pasaran yang berasal dari bahan-bahan kimia, sehingga menyebabkan dampak yang kurang baik terhadap tanaman maupun lingkungan (Wulandari, 2010), untuk itu menurut Lusiana et al., (2013) dibutuhkan ZPT alami yang mengandung senyawa organik. Menurut Anjorin et al., (2010), cit. Ashfaq et al., (2012), daun kelor merupakan salah satu bahan organik yang kaya zeatin, sitokinin, askorbat, fenolik, dan mineral seperti $\mathrm{Ca}, \mathrm{K}$, dan $\mathrm{Fe}$ yang memicu pertumbuhan tanaman. Salah satu bentuk dari sitokinin yang terjadi secara alam pada tanaman adalah zeatin.

Daun kelor segar yang dikumpulkan dari berbagai penjuru telah terbukt memiliki kandungan zeatin tinggi dengan konsentrasi zeatin antara 5-200 mcg/g daun (El Awady, 2003 cit. Culver, 2012).

Ekstrak daun kelor hanya dapat digunakan dalam waktu tidak lebih dari lima jam setelah pembuatan, sedangkan waktu perendaman bahan setek sirih dalam ektrak daun kelor belum diketahui. Selain itu, bagian sulur yang dapa memberikan pertumbuhan setek sirih yang baik juga belum diketahui sehingga perlu dilakukan penelitian yang mengkaji tentang pengaruh bagian setek dan lama perendaman dalam ekstrak daun kelor terhadap pertumbuhan bibit sirih daun. Penelitian ini bertujuan untuk mengetahui pengaruh bagian setek dan lama perendaman dalam ekstrak daun kelor terhadap pertumbuhan bibit sirih daun serta memperoleh bagian setek dan lama perendaman dalam ekstrak daun kelor yang memberikan pertumbuhan bibit sirih daun yang terbaik.

\section{Metode}

Penelitian dilaksanakan pada bulan Januari sampai April 2016 di kebun percobaan Fakultas Pertanian, Universitas Timor, Kelurahan Sasi, Kecamatan Kota Kefamenanu, Kabupaten Timor Tengah Utara (TTU). Percobaan po menggunakan Rancangan Acak Kelompok (RAK) faktorial 2 × 3 dengan 7 ulangan. Faktor pertama adalah bagian setek, terdiri dari dua aras, yaitu; pucuk $\left(b_{1}\right)$, dan tengah $\left(b_{2}\right)$. Faktor kedua adalah lama perendaman dalam ekstrak daun kelor terdiri dari tiga aras, yaitu: 1 jam $\left(\mathrm{j}_{1}\right), 3$ jam $\left(\mathrm{j}_{2}\right)$, dan 5 jam $\left(\mathrm{j}_{3}\right)$. Kombinasi perlakuannya adalah $b_{1} j_{1}, b_{1} j_{2}, b_{1} j_{3}, b_{2} j_{1}, b_{2} j_{2}$, dan $b_{2} j_{3}$.

Tanaman induk untuk bahan setek berumur \pm 2 tahun, berasal dari desa Bijeli, Kecamatan Noemuti, Kabupaten TTU. Bahan setek sirih daun berasal dar sulur panjat, terdiri dari bagian pucuk 21 potong, tengah 21 potong dan panjang setek $\pm 25 \mathrm{~cm}$. Daun kelor juga berasal dari lokasi yang sama, diambil dari tunas yang berumur 35 hari. Batang sirih daun dipotong dengan pisau menjadi dua bagian yang masing-masing panjangnya $\pm 25 \mathrm{~cm}$, memotong pangkal setek membentuk sudut $45^{\circ}$ agar permukaan tempat tumbuhnya akar lebih luas (Rismawati dan Syakhril, 2012). Semua daun dipotong untuk mengurang transpirasi (Sudewo, 2010). Media tanam terdiri dari tanah, pupuk kandang sapi, dan pasir dengan perbandingan volume 2:1:1. Tanah yang digunakan sebagai media diambil dari kebun percobaan Fakultas Pertanian Universitas Timor Pupuk kandang sapi diambil dari desa Tapen Pah, Kecamatan Insana, memiliki ciri berwarna hitam menyerupai tanah dan telah terdekomposisi sebanyak 100 $\mathrm{kg}$, dijemur selama 2 hari lalu dihaluskan dan diayak menggunakan ayakan dengan ukuran Astm E: 11, Aperture: 1,00 mm, Mesh No. 18. Pasir yang digunakan diambil dari kali Noenebu, desa Tapen Pah, Kecamatan Insana yang diayak menggunakan ayakan yang sama.

Penyiapan ekstrak daun kelor berasal dari tunas yang berumur 35 hari Menghancurkan daun kelor menggunakan blender dan dicampur dengan aquade 1 liter untuk $1 \mathrm{~kg}$ bahan. Bahan yang telah hancur dibungkus dengan kain, kemudian diremas-remas hingga diperoleh larutan. Menyaring larutan dengan menggunakan kertas filter Whatman No 2. Larutan hasil penyaringan diaduk selama 15 menit kemudian diencerkan dengan perbandingan 1:32 volume, selanjutnya dapat digunakan untuk merendam bagian stek. Bahan stek direndamMencampur hasil ayakan tanah, pasir dan pupuk kandang sapi dengan perbandingan volume $2: 1: 1$, kemudian dimasukkan ke dalam polybag berukuran $15 \mathrm{~cm}$ x $20 \mathrm{~cm}$ (Manek, 2008). Menyusun polybag dalam petak-petak percobaan sesuai denah penelitian di tempat persemaian.

Memotong batang sirih daun dengan pisau menjadi dua bagian yang masing-masing panjangnya $\pm 25 \mathrm{~cm}$, memotong pangkal setek membentuk sudu $45^{\circ}$ agar permukaan tempat tumbuhnya akar lebih luas (Rismawati dan Syakhril, 2012). Semua daun dipotong untuk mengurangi transpirasi (Sudewo, 2010).

dalam wadah berisi larutan ekstrak daun kelor dengan lama waktu sesuai perlakuan yaitu 14 batang yang terdiri bagian pucuk dan tengah selama1 jam, 14 batang lainnya selama 3 jam, dan 14 batang lainnya selama 5 jam. Parameter pengamatan meliputi:

a. Jumlah daun yakni menghitung semua daun yang tumbuh pada tanaman, yang dilakukan 3 kali pada saat tanaman berumur 30, 60, dan 90 HST.

b. Indeks luas daun dilakukan saat akhir penelitian, dengan menghitung luas daun, selanjutnya dihitung dengan persamaan:

$$
I L D=\frac{L a}{G a}
$$

Keterangan: ILD: Indeks luas daun; La: Luas daun $\left(\mathrm{cm}^{2}\right)$; Ga: Luas Tanah.

c. Berat kering daun, diperoleh dari penimbangan bagian daun tanaman yang telah dioven pada suhu $80^{\circ} \mathrm{C}$ selama 48 jam hingga mencapai berat konstan.

d. Bobot daun khas, diperoleh dari hasil bagi antara bobot kering daun per luas area daun yang dapat dinyatakan atau dirumuskan dengan persamaan:

$$
B D K=\frac{W l}{L a}
$$

Keterangan: BDK : Bobot daun Khas; Wl : Berat kering daun; La : Luas daun.

e. Tinggi tunas, dilakukan dengan mengukur dari pangkal batang sampai ujung daun paling tinggi menggunakan penggaris $60 \mathrm{~cm}$ pada tunas saat berumur 30, 60, dan 90 HST.

f. Jumlah tunas, dihitung dari semua tunas yang tumbuh pada tanaman sampel Jumlah tunas dihitung 1 kali selama penelitian yakni 90 HST.

g. Berat kering tunas, diukur dengan cara semua organ tunas dioven dengan suhu $80^{\circ} \mathrm{C}$ selama 48 jam hingga konstan, kemudian ditimbang untuk mengetahui berat kering organ tunas.

h. Laju pertumbuhan tunas, dihitung dengan cara membagi berat kering semua tunas dengan jumlah hari selama penelitian. Laju pertumbuhan tunas dapat dihitung dengan rumus:

$$
L P T=\frac{B k t}{T}
$$

Keterangan: LPT : Laju pertumbuhan tunas; Bkt : Berat kering tunas; T Total minggu selama penelitian.

i. Berat kering akar, diukur setelah penimbangan berat segar akar dilanjutkan dengan mengeringkannya di oven pada suhu $80^{\circ} \mathrm{C}$ selama 48 jam hingga mencapai berat konstan, dan menimbang berat kering akar menggunakan timbangan analitik.

j. Rasio tajuk akar, diperoleh dari hasil bagi antara berat kering tunas dengan berat kering akar yang dapat dinyatakan atau dirumuskan dengan persamaan: $S R=\frac{B k t}{B k a}$ 
Keterangan: SR : Rasio tajuk akar; Bkt : Berat kering tunas; Bka : Berat kering akar.

Data hasil pengamatan kemudian dianalisis dengan menggunakan sidik ragam (Anova) RAK faktorial. Rata-rata perlakuan selanjutnya diuji lanjut dengan menggunakan Duncan Multiple Range Test (DMRT) dengan tingkat signifikan 5\% sesuai petunjuk Gomez dan Gomez (1995). Analisis data menggunakan program SAS 9.1.

\section{Hasil dan Pembahasan}

\subsection{Jumlah Daun}

Jumlah daun meningkat seiring bertambahnya umur tunas, hasil sidik ragam menunjukkan interaksi antara bagian setek dan lama perendaman ekstrak kelor terjadi pada pengamatan 60 HST. Setek bagian tengah yang direndam selama 3 jam memiliki daun yang paling banyak pada pengamatan $30 \mathrm{HST}$, sedangkan pada pengamatan $60 \mathrm{HST}$ dan $90 \mathrm{HST}$ setek bagian pucuk yang direndam selama 3 jam memiliki daun yang paling banyak.

Tabel 1. Jumlah daun (helai)

\begin{tabular}{|c|c|c|c|c|c|}
\hline \multirow{2}{*}{$\begin{array}{c}\text { Waktu } \\
\text { pengamatan }\end{array}$} & \multirow{2}{*}{ Bagian Setek } & \multicolumn{3}{|c|}{ Lama Perendaman (Jam) } & \multirow{2}{*}{ Rerata } \\
\hline & & 1 & 3 & 5 & \\
\hline \multirow{3}{*}{$30 \mathrm{HST}$} & Pucuk & 3,29 & 4,86 & 4,57 & $4,24 \mathrm{a}$ \\
\hline & Tengah & 4,57 & 4,86 & 3,43 & $4,29 \mathrm{a}$ \\
\hline & Rerata & $3,93 \mathrm{a}$ & $4,86 \mathrm{a}$ & $4,00 \mathrm{a}$ & $(-)$ \\
\hline \multirow{3}{*}{$60 \mathrm{HST}$} & Pucuk & $7,14 \mathrm{~b}$ & $10,71 \mathrm{a}$ & $10,57 \mathrm{a}$ & $9,48 \mathrm{a}$ \\
\hline & Tengah & $8,29 \mathrm{ab}$ & $8,43 \mathrm{ab}$ & $7,00 \mathrm{~b}$ & $7,90 \mathrm{a}$ \\
\hline & Rerata & $7,71 \mathrm{a}$ & $9,57 \mathrm{a}$ & $8,79 \mathrm{a}$ & $(+)$ \\
\hline \multirow{3}{*}{$90 \mathrm{HST}$} & Pucuk & 14,57 & 19,57 & 17,71 & $17,29 \mathrm{a}$ \\
\hline & Tengah & 14,00 & 17,00 & 12,71 & $14,57 \mathrm{a}$ \\
\hline & Rerata & $14,29 \mathrm{a}$ & $18,29 \mathrm{a}$ & $15,21 \mathrm{a}$ & $(-)$ \\
\hline
\end{tabular}

\subsection{Indeks Luas Daun}

Hasil sidik ragam (Anova) menunjukkan tidak terjadi interaksi antara bagian setek dan lama perendaman ekstrak kelor pada indeks luas daun. Setek bagan tengah memiliki nilai ILD paling tinggi dan berbeda nyata dengan setek bagian pucuk. Setek yang direndam selama 1 jama memiliki nilai ILD cenderung lebih tinggi dibandikan dengan perlakuan lainnya.

Nilai ILD > 1 menggambarkan adanya saling menaungi di antara daun yang mengakibatkan daun yang ternaungi pada lapisan bawah tajuk mendapat cahaya yang kurang dan karenanya dapat mempunyai laju fotosintesis yang lebih rendah dari daun yang tidak ternaungi. Tetapi perlu diingat bahwa ILD $\leq 1$ tidak berarti tanpa naungan. Ini sangat tergantung pada morfologi daun (bentuk dan posisi daun).

\section{$\underline{\text { Tabel 2. Indeks luas daun }}$}

\begin{tabular}{ccccc}
\hline \multirow{2}{*}{ Bagian Setek } & \multicolumn{3}{c}{ Lama perendaman (Jam) } & \multirow{2}{*}{ Rerata } \\
\cline { 2 - 4 } & 1 & 3 & 5 & \\
\hline Pucuk & 0,98 & 0,65 & 0,92 & $0,85 \mathrm{~b}$ \\
Tengah & 1,21 & 1,21 & 0,94 & $1,12 \mathrm{a}$ \\
\hline Rerata & $1,10 \mathrm{a}$ & $0,93 \mathrm{a}$ & $0,93 \mathrm{a}$ & $(-)$ \\
\hline Keterangan: & Angka pada baris dan kolom diikuti huruf sama tidak berbeda pada taraf nyata $(\alpha) 5 \%$
\end{tabular}
menurut uji DMRT. (-) : Tidak terjadi interaksi antar faktor.

\subsection{Berat Kering Daun}

Hasil sidik ragam (Anova) menunjukkan tidak terjadi interaksi antar bagian setek dan lama perendaman ekstrak kelor terhadap berat kering daun. Berat kering daun paling tinggi dihasilkan oleh perlakuan setek bagian tengah yang direndam selama 3 jam dibandingkan dengan perlakuan lainnya.

Tabel 3. Berat kering daun $(\mathrm{g})$

\begin{tabular}{ccccc}
\hline \multirow{2}{*}{ Bagian Setek } & \multicolumn{3}{c}{ Lama Perendaman (Jam) } & \multirow{2}{*}{ Rerata } \\
\cline { 2 - 4 } & 1 & 3 & 5 & \\
\hline Pucuk & 0,82 & 0,94 & 0,94 & $0,90 \mathrm{a}$ \\
Tengah & 1,14 & 1,25 & 0,71 & $1,03 \mathrm{a}$ \\
\hline Rerata & 0,98 a & 1,09 a & 0,83 a & $(-)$ \\
\hline Keterangan: & Angka pada baris dan kolom diikuti huruf sama tidak berbeda pada taraf nyata $(\alpha) 5 \%$ \\
& menurut uji DMRT. (-): Tidak terjadi interaksi antar faktor.
\end{tabular}

\subsection{Bobot Daun Khas}

Hasil sidik ragam (Anova) menunjukkan bobot daun khas tidak nyata mempengaruhi bagian setek dan lama perendaman ekstrak daun kelor, bagian setek pucuk memiliki bobot daun khas yang paling tinggi dari setek bagian tengah. Sedangkan setek yang direndam selama 3 jam memiliki bobot daun khas yang paling tinggi dibandingkan dengan perlakuan lainnya.

Bobot daun khas merupakan hasil bagi antara berat kering daun dengan luas daun. Bobot daun khas mengandung informasi tentang ketebalan daun. Semakin tinggi bobot daun khas berarti semakin tinggi pula ketebalan daun, menunjukkan jumlah organel fotosintesis berlimpah dalam daun.
Tabel 4. Bobot daun khas $\left(\mathrm{g} / \mathrm{cm}^{2}\right)$

\begin{tabular}{ccccc}
\hline \multirow{2}{*}{ Bagian Setek } & \multicolumn{3}{c}{ Lama Perendaman (Jam) } & \multirow{2}{*}{ Rerata } \\
\cline { 2 - 4 } & 1 & 3 & 5 & \\
\hline Pucuk & 0,0046 & 0,0069 & 0,0059 & $0,0058 \mathrm{a}$ \\
Tengah & 0,0054 & 0,0059 & 0,0044 & $0,0052 \mathrm{a}$ \\
\hline Rerata & 0,0050 a & 0,0064 a & 0,0052 a & $(-)$ \\
\hline Keterangan: & Angka pada baris dan kolom diikuti huruf sama tidak berbeda pada taraf nyata $(\alpha) 5 \%$ \\
& menurut uji DMRT. $(-)$ : Tidak terjadi interaksi antar faktor.
\end{tabular}

\subsection{Tinggi Tunas}

Tunas sirih terus bertambah tinggi bersamaan dengan pertambahan waktu, hasil sidik ragam (Anova) tidak terjadi interaksi antara bagian setek dengan lama perendaman terhadap tinggi tunas pada saat pengamatan 30 HST sampai dengan 90 HST. Bagian setek nyata mempengaruhi tinggi tunas pada pengamatan 30 dan $60 \mathrm{HST}$, sedangkan lama perendaman tidak nyata mempengaruhi tinggi tunas. Setek sirih yang berasal dari bagian tengah yang direndam selama 1 jam selalu paling tinggi pada setiap pengamatan.

\section{Tabel 5. Tinggi tunas $(\mathrm{cm})$}

\begin{tabular}{|c|c|c|c|c|c|}
\hline \multirow{2}{*}{$\begin{array}{c}\text { Waktu } \\
\text { pengamatan }\end{array}$} & \multirow{2}{*}{$\begin{array}{l}\text { Bagian } \\
\text { Setek }\end{array}$} & \multicolumn{3}{|c|}{ Lama Perendaman (Jam) } & \multirow[t]{2}{*}{ Rerata } \\
\hline & & 1 & 3 & 5 & \\
\hline \multirow{3}{*}{$30 \mathrm{HST}$} & Pucuk & 3,14 & 3,27 & 4,21 & $3,54 \mathrm{~b}$ \\
\hline & Tengah & 3,97 & 5,13 & 4,14 & $4,75 \mathrm{a}$ \\
\hline & Rerata & $4,05 \mathrm{a}$ & $4,20 \mathrm{a}$ & $4,17 \mathrm{a}$ & $(-)$ \\
\hline \multirow{3}{*}{$60 \mathrm{HST}$} & Pucuk & 8,02 & 5,88 & 8,02 & $7,31 \mathrm{~b}$ \\
\hline & Tengah & 9,95 & 9,71 & 8,17 & $9,28 \mathrm{a}$ \\
\hline & Rerata & $8,99 \mathrm{a}$ & $7,79 \mathrm{a}$ & $8,10 \mathrm{a}$ & $(-)$ \\
\hline \multirow{3}{*}{$90 \mathrm{HST}$} & Pucuk & 18,45 & 11,66 & 14,84 & $14,99 \mathrm{a}$ \\
\hline & Tengah & 17,71 & 20,61 & 14,50 & $17,61 \mathrm{a}$ \\
\hline & Rerata & $18,08 \mathrm{a}$ & $16,14 \mathrm{a}$ & $14,67 \mathrm{a}$ & $(-)$ \\
\hline
\end{tabular}

Keterangan: Angka pada baris dan kolom diikuti huruf sama tidak berbeda pada taraf nyata $(\alpha) 5 \%$ menurut uji DMRT. (-): Tidak terjadi interaksi antar faktor.

Tunas sirih terus bertambah tinggi bersamaan dengan pertambahan waktu, hasil sidik ragam (Anova) tidak terjadi interaksi antara bagian setek dengan lama perendaman terhadap tinggi tunas pada saat pengamatan 30 HST sampai dengan 90 HST. Bagian setek nyata mempengaruhi tinggi tunas pada pengamatan 30 dan 60 HST, sedangkan lama perendaman tidak nyata mempengaruhi tinggi tunas. Setek sirih yang berasal dari bagian tengah yang direndam selama 1 jam selalu paling tinggi pada setiap pengamatan.

\subsection{Jumlah Tunas}

Hasil sidik ragam (Anova) menunjukkan terjadi interaksi antara bagian setek dengan lama perendaman ekstrak kelor pada jumlah tunas. Setek dari bagian pucuk yang direndam selama 3 jam memiliki jumlah tunas yang paling banyak dari kombinasi perlakuan lainnya.

Tabel 6. Jumlah tunas

\begin{tabular}{ccccc}
\hline \multirow{2}{*}{ Bagian Setek } & \multicolumn{3}{c}{ Lama Perendaman (Jam) } & \multirow{2}{*}{ Rerata } \\
\cline { 2 - 4 } & 1 & 3 & 5 & \\
\hline Pucuk & $2,29 \mathrm{~b}$ & $4,29 \mathrm{a}$ & $3,00 \mathrm{~b}$ & $3,19 \mathrm{a}$ \\
Tengah & $2,43 \mathrm{~b}$ & $2,14 \mathrm{~b}$ & $2,43 \mathrm{~b}$ & $2,33 \mathrm{~b}$ \\
\hline Rerata & $2,36 \mathrm{~b}$ & $3,21 \mathrm{a}$ & $2,71 \mathrm{ab}$ & $(+)$ \\
\hline Keterangan: & Angka pada baris dan kolom diikuti huruf sama tidak berbeda pada taraf nyata $(\alpha) 5 \%$
\end{tabular}
menurut uji DMRT. (+): Terjadi interaksi antar faktor.

\subsection{Berat Kering Tunas}

Hasil sidik ragam (Anova) menunjukkan tidak terjadi pengaruh interaksi antara bagian setek dengan lama perendaman ekstrak kelor pada berat kering tunas. Setek bagian tengah yang direndam selama 3 jam memiliki berat kering tunas yang cenderung lebih berat dari perlakuan lainnya.

Tabel 7. Berat kering tunas $(\mathrm{g})$

\begin{tabular}{ccccc}
\hline \multirow{2}{*}{ Bagian Setek } & \multicolumn{3}{c}{ Lama Perendaman (Jam) } & \multirow{2}{*}{ Rerata } \\
\cline { 2 - 4 } & 1 & 3 & 5 & \\
\hline Pucuk & 1,11 & 1,23 & 1,16 & $1,17 \mathrm{a}$ \\
Tengah & 1,52 & 1,76 & 0,94 & $1,41 \mathrm{a}$ \\
\hline Rerata & 1,32 a & 1,50 a & 1,05 a & $(-)$ \\
\hline Keterangan: & Angka pada baris dan kolom diikuti huruf sama tidak berbeda pada taraf nyata $(\alpha) 5 \%$
\end{tabular}
Angka pada baris dan kolom diikuti huruf sama tidak ber
menurut uji DMRT. (-): Tidak terjadi interaksi antar faktor.

\subsection{Laju Pertumbuhan Tunas}

Hasil sidik ragam (Anova) tidak terjadi beda nyata pada perlakuan bagian setek dan lama perendaman ekstrak kelor. Setek bagian tengah memiliki laju pertumbuhan tunas paling tinggi dari setek bagian pucuk, sedangkan setek yang direndam selama 3 jam memiliki laju pertumbuhan tunas paling tingg dibandingkan dengan setek yang direndam selama 5 jam memiliki laju pertumbuhan paling rendah.

Laju pertumbuhan tanaman adalah kemampuan tanaman menghasilkan bahan kering hasil asimilasi tiap satuan luas lahan dalam satuan waktu (Gardner et al., 1991). Menurut Salisbury dan Ross (1992) bahwa laju pertumbuhan pada awalnya lambat tetapi kemudian akan meningkat terus dan menurun kembal setelah memasuki fase pematangan biji. 
Tabel 8. Laju pertumbuhan tunas ( $\mathrm{g} /$ minggu)

\begin{tabular}{ccccc}
\hline \multirow{2}{*}{ Bagian Setek } & \multicolumn{3}{c}{ Lama Perendaman (Jam) } & \multirow{2}{*}{ Rerata } \\
\cline { 2 - 4 } & 1 & 3 & 5 & \\
\hline Pucuk & 0,17 & 0,21 & 0,19 & 0,19 a \\
Tengah & 0,26 & 0,24 & 0,16 & $0,22 \mathrm{a}$ \\
\hline Rerata & 0,22 a & 0,23 a & 0,18 a & $(-)$ \\
\hline Keterangan: & Angka pada baris dan kolom diikuti huruf sama tidak berbeda pada taraf nyata $(\alpha) 5 \%$
\end{tabular}
Angka pada baris dan kolom diikuti huruf sama tidak ber
menurut uji DMRT. (-): Tidak terjadi interaksi antar faktor.

\subsection{Berat Kering Akar}

Hasil sidik ragam (Anova) menunjukkan tidak terjadi pengaruh interaksi antara bagian setek dan lama perendaman ekstrak daun kelor terhadapat berat kering akar. Setek bagian tengah memiliki berat kering akar yang cenderung lebih berat dibandingan dengan setek bagian pucuk, sedangkan setek yang direndam selama 1 jam memiliki berat kering akar yang paling berat dan setek yang direndam selama 5 jam memiliki berat kering akar paling ringan.

Tabel 9. Berat kering akar $(\mathrm{g})$

\begin{tabular}{ccccc}
\hline \multirow{2}{*}{ Bagian Setek } & \multicolumn{3}{c}{ Lama Perendaman (Jam) } & \multirow{2}{*}{ Rerata } \\
\cline { 2 - 4 } & 1 & 3 & 5 & \\
\hline Pucuk & 0,23 & 0,29 & 0,27 & 0,26 a \\
Tengah & 0,39 & 0,32 & 0,23 & 0,31 a \\
\hline Rerata & 0,31 a & 0,30 a & 0,25 a & $(-)$ \\
\hline Keterangan: $\quad$ Angka pada baris dan & kolom diikuti huruf sama tidak berbeda pada taraf nyata $(\alpha) 5 \%$
\end{tabular}
menurut uji DMRT. (-): Tidak terjadi interaksi antar faktor.

\subsection{Rasio Tajuk Akar}

Hasil sidik ragam (Anova) menunjukkan tidak terjadi pengaruh interaksi antara bagian setek dan lama perendaman ekstrak daun kelor terhadapat rasio tajuk akar. Setek bagian tengah memiliki rasio tajuk akar yang cenderung lebih tinggi dibandingan dengan setek bagian pucuk, sedangkan setek yang direndam selama 3 jam memiliki rasio tajuk akar yang paling tinggi dan setek yang direndam selama 5 jam memiliki rasio tajuk akar paling ringan.

Tabel 10. Rasio tajuk akar

\begin{tabular}{|c|c|c|c|c|}
\hline \multirow{2}{*}{ Bagian Setek } & \multicolumn{3}{|c|}{ Lama Perendaman (Jam) } & \multirow{2}{*}{ Rerata } \\
\hline & 1 & 3 & 5 & \\
\hline Pucuk & 4,3053 & 4,5481 & 3,6671 & $4,1735 \mathrm{a}$ \\
\hline Tengah & 4,7227 & 5,0122 & 4,2017 & $4,6455 \mathrm{a}$ \\
\hline Rerata & $4,5140 \mathrm{a}$ & $4,7801 \mathrm{a}$ & $3,9344 \mathrm{a}$ & $(-)$ \\
\hline
\end{tabular}
menurut uji DMRT. (-): Tidak terjadi interaksi antar faktor.

\subsection{Pembahasan}

Interaksi antar perlakuan yang terjadi pada jumlah tunas juga menunjukkan bahwa setek bagian pucuk yang direndam dalam ektrak daun kelor selama 3 jam menghasilkan jumlah tunas terbanyak, namun dari analisis korelasi tidak memberi sumbangan besar terhadap peningkatan bobot kering tunas $\left(\mathrm{R}^{2}=\right.$ 0,002), namun jumlah daun $\left(\mathrm{R}^{2}=0,49\right)$ dan tinggi tunas yang memiliki sumbangan lebih besar $\left(\mathrm{R}^{2}=0,47\right)$.

Bobot kering daun memiliki sumbangan dalam meningkatkan berat kering tunas $\left(R^{2}=0,99\right)$, dan juga dipengaruhi oleh bobot daun khas $\left(R^{2}=0,53\right)$, sedangkan luas daun tidak banyak memberikan sumbangan pada berat kering tunas, $\left(R^{2}=0,40\right)$. Diduga waktu bertunas mempengaruhi bobot daun khas karena tunas yang tumbuh paling cepat memiliki bobot daun khas paling berat, indikasi bahwa daunnya lebih tebal dan mampu memaksimalkan kemampuan tanaman dalam melakukan proses fotosintesis.

Berat kering akar juga berperan dalam meningkatkan berat kering tunas $\left(\mathrm{R}^{2}\right.$ $=0,54$ ), pengamatan lebih lanjut menunjukkan bahwa tanaman yang berasal dari setek bagian tengah dengan lama perendaman 3 jam memiliki rasio tajuk akar paling besar, ini mendukung temuan Loomis (1953) dan Murata (1969) cit., Gardner et al., (1991), bahwa pertumbuhan tajuk lebih pesat bila tersedia air dan $\mathrm{N}$ yang cukup (lingkungan yang lebih mendukung).

\section{Simpulan}

Terjadi pengaruh interaksi antara bagian setek dengan lama perendaman ekstrak daun kelor terhadap parameter diameter batang 30 dan 60 HST, jumlah daun 60 HST serta jumlah tunas. Setek yang berasal dari bagian tengah dengan lama perendaman 3 jam menghasil pertumbuhan bibit sirih yang paling baik, laju pertumbuhan tunas $(0,24 \mathrm{~g} / \mathrm{minggu})$, laju asimilasi bersih $(0,0044$ $\mathrm{g} / \mathrm{cm}^{2} /$ minggu), Rasio tajuk akar (5,01 g) bobot kering tunas $(1,76 \mathrm{~g})$.

\section{Pustaka}

Ashfaq. M, Basra M.A. S, AND Ashfaq. U. 2012. Moringa: A Miracle Plant for Agro-forestry. Department of Entomology, University of Agriculture, Faisalabad, Pakistan.

Culver M, Fanuel T dan Chiteka A Z. 2012. Effect of Moringa Extract on Growth and Yield of Tomato. Greener Journal of Agricultural Sciences. 2(5):207211.

Danu dan Nurhasybi. 2003. Potensi benih generatif dan vegetatif dalam pembangunan hutan tanaman. Makalah Temu Lapang dan Ekspose Hasi Penelitian UPT Badan Litbang Kehutanan. Wilayah Sumatera, Palembang.
Gardner FP, Pearce RB, and Mitchell RL. 1991. Physiology of Crop Plants. Universitas Indonesia Press. Jakarta.

Gomez, K. A. and Gomez, A. A. 1995. Prosedur Statistik Untuk Penelitian Pertanian. Edisi ke 2. UI Press: Jakarta.

Loomis, W. E. 1953. Growth and Differentiation In Plants. Ames : Iowa State Collage Press.

Lusiana, Riza Linda, Mukarlina. 2013. Respon Pertumbuhan Stek Batang Sirih Merah (Piper crocatum Ruiz dan Pav). setelah Direndam dalam Urin Sapi. Jurnal Protobiont 2013 Vol 2 (3): 157-160.

Manek, X. H., 2008. Pengaruh Jenis Media Tanam Dan Bahan Setek Terhadap Pertumbuhan Bibit Sirih Buah. Skripsi Program Studi Agroteknologi Fakultas Pertanian Universitas Timor. Kefamenanu.

Prastowo, N. H, Roshetko, J. N., Murung, G. E. S., Nugraha. E., Tukan, J. M., Harum, F. 2006. Teknik Pembibitan dan Perbanyakan Vegetatif Tanaman Buah. World Agroforestry Centre [ICRAF] \& Winrock International. Bogor. Indonesia.

Rismawati dan Syakhril. 2012. Respons Asal Bahan Stek Sirih Merah (Piper crocatum Ruiz and Pav.) Terhadap Konsentrasi Rootone F. Prodi Agroteknologi Pertanian, Fakultas Pertanian Universitas Mulawarman. Samarinda.

Salisbury, F. B. and Cleon W. Ross, 1992. Fisiologi Tumbuhan Edisi Terjemahan, ITB Bandung, Bandung.

Sudewo, B. 2010. Basmi Penyakit dengan Sirih Merah (Piper crocatum). PT. Agromedia. Pustaka Yogyakarta.

Suwandiyati. D. N. 2009. Pengaruh Asal Bahan Setek Dan Dosis Pupuk Kandang Sapi Terhadap Pertumbuhan Bibit Nilam (Pogostemon cablin Benth) SkripsiJurusan/Program Studi Agronomi Fakultas Pertanian Universitas Sebelas Maret. Surakarta.

Wulandari Y. 2010. Pengaruh Ekstrak Biji Kelor (Moringa Oleifera, Lamk) Terhadap Pertumbuhan Dan Serangan Hama Bibit Kopi Robusta (Coffea Canephora, Pierre). Skripsi Jurusan Budidaya Pertanian Fakultas Pertanian Universitas Jember. Jember. 